Published in final edited form as:

Am J Intellect Dev Disabil. 2013 November ; 118(6): 475-495. doi:10.1352/1944.7558-118.6.475.

\title{
Physiological Arousal in Autism and Fragile X Syndrome: Group Comparisons and Links With Pragmatic Language
}

\author{
Jessica Klusek, \\ Frank Porter Graham Child Development Institute
}

Gary E. Martin, and

University of North Carolina at Chapel Hill

\section{Molly Losh}

Northwestern University; Roxelyn and Richard Pepper Department of Communication Sciences and Disorders, 2240 Campus Drive, Northwestern University, Evanston, IL, 60208

Molly Losh: m-losh@northwestern.com

\begin{abstract}
This study tested the hypothesis that pragmatic (i.e., social) language impairment is linked to arousal dysregulation in autism spectrum disorder (ASD) and fragile X syndrome (FXS). Forty boys with ASD, 39 with FXS, and 28 with typical development (TD), aged 4-15 years, participated. Boys with FXS were hyperaroused compared to boys with TD but did not differ from boys with ASD. Dampened vagal tone predicted pragmatic impairment in ASD, and associations emerged between cardiac activity and receptive/expressive vocabulary across groups. Findings support autonomic dysfunction as a mechanism underlying pragmatic impairment in ASD and suggest that biophysiological profiles are shared in ASD and FXS, which has implications for understanding the role of fragile X mental retardation- 1 (FMRl, the FXS gene) in the pathophysiology of ASD.
\end{abstract}

\section{Keywords}

autism; ASD; fragile X syndrome; arousal; vagal tone; heart rate; pragmatic language; social communication; endophenotype

\footnotetext{
Fragile X syndrome (FXS) is a monogenic disorder associated with significantly increased risk for autism spectrum disorder (ASD; Cohen, Pichard, \& Tordjman, 2005). Pragmatic language impairment is seen in both ASD and FXS (Landa, 2000; Losh, Martin, Klusek, Hogan-Brown, \& Sideris, 2012; Sudhalter \& Belser, 2001), yet it is unknown whether such impairments arise from similar underlying impairments. Physiological dysregulation (e.g., elevated heart rate and differences in the functioning of the parasympathetic "rest and restore" system) has been documented in FXS and idiopathic ASD and, in FXS, has been hypothesized to be a causal factor in pragmatic language impairments (e.g., Belser \& Sudhalter, 1995). The present study investigated the role of physiological dysregulation in pragmatic language deficits in ASD and FXS, examining physiological arousal in relation to clinically based and standardized assessments of pragmatic language across groups. Further understanding of arousal, a biophysiological marker for stress, as a mechanism linked with pragmatic language impairments of ASD and FXS may have implications for the development of targeted interventions and lend insight into shared biological pathways in ASD and FXS that can be traced back to the gene that causes FXS, fragile X mental retardation-1 (FMRI).
} 


\section{Genetic Basis of ASD and FXS}

ASD is characterized by atypical social and communicative development along with repetitive and restricted behavioral patterns (American Psychiatric Association, 2013). Affecting approximately 1 in 88 individuals, ASD is seen at high levels, and there is an urgent need to understand the etiological basis of the disorder (CDC, 2012). Evidence supports a strong genetic component in the etiology of ASD although the exact genetic underpinnings still remain undefined (Devlin \& Scherer, 2012). The genetic basis of ASD is thought to be heterogeneous and complex with many different gene-gene and geneenvironment interactions leading to the common phenotypic endpoint of ASD (Abrahams \& Geschwind, 2008). Single-gene disorders, such as FXS, are implicated in about $10 \%$ of cases of ASD (Betancur, 2011). The study of ASD within the context of associated genetic conditions provides a better-understood genetic paradigm for studying ASD, which may provide a starting point for pinning down pathophysiological mechanisms (Abrahams \& Geschwind, 2008; Hagerman, Hoem, \& Hagerman, 2010).

While the etiological basis of ASD is complex and heterogeneous, FXS can be traced back to a single genetic cause: a trinucleotide expansion on the FMRl gene (Pieretti et al., 1991). This expansion silences the gene and halts the production of fragile $\mathrm{X}$ mental retardation protein (FMRP), which is highly expressed in the brain and is thought to play a role in synaptic development (Hagerman \& Hagerman, 2002). Deficiency in FMRP appears to underlie the neurobehavioral profile of FXS, which includes intellectual disability, language impairment, social difficulties, anxiety, and hyperactivity (Baumgardner, Reiss, Freund, \& Abrams, 1995; Hagerman, 2002; Reiss \& Dant, 2003).

Strikingly, 50\%-75\% of individuals with FXS meet criteria for ASD, and those who do not reach diagnostic thresholds nevertheless show symptoms consistent with ASD, such as reduced eye gaze and repetitive behaviors (Hagerman et al., 1986; Hall, Lightbody, \& Reiss, 2008; Harris et al., 2008). This significantly elevated risk for ASD suggests that the FMRI mutation may play a role in the development of autistic symptoms, potentially through interactions with other genes that are involved in ASD (Hagerman, Au, \& Hagerman, 2011). For example, FMRP assists in the translation of several proteins that are dysregulated in idiopathic ASD (e.g., neuroexin, CYFIP, PTEN), and the absence of FMRP in FXS has a detrimental effect on the normal expression of other genes (see Hagerman et al., 2010). In fact, a large number of autism susceptibility genes are known interactors with FMRI (Darnell \& Klann, 2013; Darnell et al., 2011; Iossifov et al., 2012). The FMRI mutation may therefore disrupt the normal function of a number of autism susceptibility genes, lowering the threshold of interacting genetic effects needed to produce ASD. In this way, FXS provides a simplified genetic model that may be useful in identifying genetic or molecular pathways implicated in ASD.

\section{Pragmatic Language in ASD and FXS}

Evidence suggests that individuals with idiopathic and FXS-associated ASD show similar symptom profiles on omnibus measures of autism symptomatology (Dissanayake, Bui, Bulhak-Paterson, Huggins, \& Loesch, 2009; Rogers, Wehner, \& Hagerman, 2001). Specific features of the language profiles associated with ASD, such as pragmatic language impairment, also appear to be shared in idiopathic ASD and ASD within the context of FXS (Losh, Martin, et al., 2012). Pragmatic language is defined as the use of language in social contexts to communicate meaning (Bates, 1976; McTear \& Conti-Ramsden, 1992; Prutting, 1982). Pragmatic language difficulties are a universally observed feature of ASD (Landa, 2000; Tager-Flusberg, Paul, \& Lord, 2005). For example, turn-taking, topic maintenance, and communicative repair skills are deficient in ASD (Adams, Green, Gilchrist, \& Cox, 
2002; Capps, Kehres, \& Sigman, 1998; Geller, 1998; Paul et al., 1987; Tager-Flusberg \& Anderson, 1991; Volden, 2004). Atypical pragmatic features such as echolalia, perseveration, and bizarre word choice are seen at increased rates in ASD (Ghaziuddin \& Leonore, 1996; Ross, 2002; Schuler \& Prizant, 1985), and narrative (storytelling) skills are impaired as well (Capps, Losh, \& Thurber, 2000; Diehl, Bennetto, \& Young, 2006; Losh \& Capps, 2003; Loveland, McEvoy, \& Tunali, 1990; Tager-Flusberg, 1995). Differences in pragmatic language use are thought to be a genetically meaningful feature of ASD, given that subclinical pragmatic differences present at increased rates among unaffected relatives of individuals with ASD (Landa et al., 1992; Losh, Childress, Lam, \& Piven, 2008) and show patterns suggestive of intrafamilial transmission (Klusek, Losh, \& Martin, 2012).

Pragmatic language deficits are also seen in FXS. For example, conversation in FXS is characterized by impaired topic maintenance (Roberts et al., 2007; Sudhalter \& Belser, 2001; Sudhalter, Cohen, Silverman, \& Wolf-Schein, 1990; Wolf-Schein et al., 1987), poor ability to repair communicative breakdowns (Abbeduto et al., 2008), and stereotyped and perseverative language (Belser \& Sudhalter, 2001; Martin et al., 2012; McDuffie et al., 2010; Roberts et al., 2007; Sudhalter et al., 1990; Wolf-Schein et al., 1987). Importantly, children with idiopathic ASD and FXS with comorbid ASD perform comparably on standardized pragmatic language assessments, and pragmatic language abilities are associated with FMRI-related genetic variation in FXS (Losh, Martin, et al., 2012). Furthermore, recent research suggests that pragmatic language profiles overlap in the broad autism phenotype and the FMRI premutation. Female carriers of the FMRI premutation and mothers of individuals with ASD exhibit conversational pragmatic language difficulties that are elevated in comparison to controls and which are not only similar in severity but also show qualitative overlap as evidenced by similar performance on pragmatic subdomains (see Losh, Klusek, et al., 2012). Together, these studies suggest that FMRl may be involved in pragmatic language impairments associated with ASD.

Although significant overlap in pragmatic language deficits in ASD and FXS has been documented (along with overlapping pragmatic language profiles in unaffected genetic carriers in FXS and ASD, i.e., parents), it is unclear whether the pragmatic impairments in these groups stem from common underlying factors; only a handful of studies have directly compared neurobiological characteristics in these disorders, and very few have related those features to pragmatic language. While arousal dysregulation has also been proposed as a mechanism underlying social deficits in idiopathic ASD (e.g., Dawson \& Lewy, 1989), most theories of ASD have focused on neurocognitive models to account for pragmatic language impairment, such as impaired social cognition or central coherence (Martin \& McDonald, 2003). On the other hand, several studies have proposed arousal dysregulation as a cause of pragmatic language difficulties in FXS (Belser \& Sudhalter, 1995; Cohen, 1995). In this model, arousal dysmodulation causes an individual to remain "on edge" during social situations, over time leading to social withdrawal and limiting opportunities to learn skills through interaction with others (Rubin \& Burgess, 1991). Given that physiological regulatory deficits have also been documented in ASD (Bal et al., 2010; Ming, Julu, Brimacombe, Connor, \& Daniels, 2005), this study explored physiological dysregulation as a predictor of pragmatic language deficits in both disorders.

\section{Physiological Arousal in ASD and FXS}

The present study focused on cardiac indices of physiological arousal: heart rate (a measure of general arousal) and respiratory sinus arrhythmia (RSA), an index of parasympathetic control of the heart via the vagal nerve (Porges, 2007). These indices of physiological functioning are thought to mark one's capacity for engagement with the social environment (Porges \& Furman, 2011). 


\section{Heart rate}

Increased general arousal, indexed by elevated heart rate, is a hallmark feature of FXS (Heilman, Harden, Zageris, Berry-Kravitz, \& Porges, 2011; Roberts, Boccia, Bailey, Hatton, \& Skinner, 2001; Roberts, Tonnsen, Robinson, \& Shinkareva, 2012). It is unclear whether heart rate is also elevated in ASD as there is great inconsistency across prior reports, possibly due to differences in sample characteristics and the heterogeneity that is characteristic of ASD. Increased heart rate has been detected in ASD in comparison to typical and developmentally delayed comparison groups (Bal et al., 2010; Goodwin et al., 2006; Mathewson et al., 2011; Woodard et al., 2012) although a number of other reports have found heart rate in ASD to be similar to that of controls (Althaus, Mulder, Mulder, Aarnoudse, \& Minderaa, 1999; Corona, Dissanayake, Arbelle, Wellington, \& Sigman, 1998; Sigman, Dissanayake, Corona, \& Espinosa, 2003). Hyperarousal is hypothesized to underlie communication deficits (e.g., Belser \& Sudhalter, 1995; Belser \& Sudhalter, 2001)although few studies have directly examined this hypothesis in ASD or FXS. One study of children with ASD found that elevated heart rate was associated with reduced use of communicative gestures (Patriquin, Scarpa, Friedman, \& Porges, 2011). Another preliminary report examining two males with FXS found that perseverative and tangential language was associated with increased arousal as indexed by skin conductance responses (Belser \& Sudhalter, 1995).

\section{Vagal tone}

The vagal nerve works as part of the parasympathetic "rest and restore" system, counteracting sympathetic "fight or flight" excitation to promote a physiological state that facilitates social engagement (see Porges \& Furman, 2011). Numerous studies of typical development link high vagal tone with enhanced social skills (e.g., Blair \& Peters, 2003; Calkins \& Keane, 2004; Kok \& Fredrickson, 2010). Reduced vagal tone is well documented in FXS (Hall, Lightbody, Huffman, Lazzeroni, \& Reiss, 2009; Heilman et al., 2011; Roberts et al., 2001; Roberts et al., 2012). Some investigations of ASD have also detected dampened vagal tone (Bal et al., 2010; Mathewson et al., 2011; Ming et al., 2005; Porges et al., 2013; Van Hecke et al., 2009) although reports are inconsistent (Althaus et al., 1999; Levine et al., 2012; Toichi \& Kamio, 2003). Diminished vagal tone has been shown to relate to poorer receptive vocabulary and social skills in children with ASD (Patriquin et al., 2011; Van Hecke et al., 2009) and with more severe autistic traits in toddlers with FXS (Roberts et al., 2012).

In addition to examining vagal activity at rest, the measurement of vagal tone specifically during social-communicative interactions can shed light on physiological adaption to social demands. In typical development (TD), children who show the greatest increases in vagal tone in response to social contexts have better receptive and expressive language abilities, and children who exhibit vagal withdrawal are more likely to present with anxiety, depression, and internalizing problems (Heilman et al., 2008; Suess \& Bornstein, 2000). Few studies have investigated physiological profiles of ASD and FXS during socialcommunicative contexts in order to determine how these profiles might relate to atypical pragmatic language features. In one study of children with FXS, Hall et al. (2009) found that vagal tone during conversation with an examiner did not relate to the extent of gaze avoidance exhibited by the children although the authors did not measure other pragmatic features. In another study of young children with ASD, vagal tone during a social listening task (child-directed speech) prospectively predicted later parent-reported socialcommunication abilities, and baseline vagal tone was predictive of later skills (Watson, Baranek, Roberts, David, \& Perryman, 2010). In sum, little is known about the role of the physiological system in pragmatic language deficits in ASD and FXS, and no studies, to our knowledge, have directly compared cardiac indicators of physiological profiles in ASD and 
FXS, limiting our understanding of biophysiological pathways that may be shared in ASD and FXS and could be linked to similar behavioral endpoints (such as pragmatic language).

\section{Study Rationale and Hypotheses}

This study addressed the hypothesis that physiological dysregulation in ASD and FXS is linked with pragmatic language impairment. The study addressed two primary questions:

1. Do cardiac indicators of physiological activity differ in boys with ASD, FXS, and TD during resting and conversational contexts? Prior to examining associations between arousal and pragmatic language in each group, it was important to establish profiles of physiological activity and determine any differences and similarities across groups. To do so, we examined group differences in heart rate and vagal tone measured at rest and during unstructured conversation with an examiner.

2. Do cardiac indicators of physiological activity predict pragmatic language impairment in ASD, FXS, and TD? We examined within-group associations between physiological activity (at rest and during conversation) and pragmatic language ability, measured in separate contexts. We also examined associations with behavioral symptoms of anxiety, which could importantly relate to both cardiac activity and pragmatic language impairment.

\section{Method}

\section{Participants}

Participants included 40 school-aged boys with idiopathic ASD, 39 boys with full-mutation FXS, and 28 boys with TD, aged 4-15 years. Participants were drawn from a larger pool of children participating in ongoing longitudinal studies of speech/language in FXS and ASD, which have been described previously (see Losh et al, 2012; Zajac, Harris, Roberts, \& Martun, 2009). Given the longitudinal design of the larger studies, in some instances an individual participant had available data from several different time points. In these cases, the time point was selected that best facilitated group-level matching on chronological age given that age has a known impact on cardiac activity (Alkon et al., 2003; Bar-Haim, Marshall, \& Fox, 2000). All participants spoke English as their primary language and were regularly using sentences of three or more words. Only boys participated in the study because girls with FXS are generally less severely affected and show more heterogeneous profiles (Hagerman, 2004). Recruitment was focused in the Eastern and Midwestern regions of the United States through local advertisement and through the Research Participant Registry Core of the Carolina Institute for Developmental Disabilities at the University of North Carolina at Chapel Hill.

Group characteristics are presented in Table 1. On average, the FXS group was older than the ASD and TD groups, and the mean age of the ASD and TD groups were similar; chronological age was controlled for statistically in group comparisons. Nonverbal mental age, as measured with the Leiter International Performance Scale-Revised (Leiter-R; Roid \& Miller, 1997), was similar in the ASD and TD groups while the boys with FXS had a significantly lower mean mental age than the other groups. Receptive and expressive vocabulary differed across groups as measured with the Peabody Picture Vocabulary TestIII (PPVT; Dunn \& Dunn, 1997) and Expressive Vocabulary Test (EVT; Williams, 1997) with FXS showing the lowest vocabulary skills, followed by the ASD group. As expected, the TD group had higher vocabulary skills than the ASD and FXS groups. The groups did not differ in race, household income, or maternal education $(p s>.135)$. Thirty percent 
(12/40) of the boys with ASD and 41\% (16/39) of the boys with FXS were reported by their caregivers to be using psychoactive medications at the time of assessment (see Table 1).

\section{Procedures}

All procedures were approved by the Institutional Review Boards of the University of North Carolina at Chapel Hill and Northwestern University. Testing took place in a research laboratory or the participant's home or school. Assessments were conducted within the context of a broader research protocol, which generally lasted 4-6 hr. In general, structured assessments that required simple, nonverbal responses (i.e., pointing), such as the PPVT, were administered first to allow some "warm up" time, followed by more interactive tasks, such as the physiological assessment. However, the protocol was flexible, and the order of assessments and number of breaks were adapted to the needs of the participant. The assessments were conducted by two trained examiners who were experienced in working with children with developmental disabilities.

Characterization of ASD-The Autism Diagnostic Observation Schedule (ADOS; Lord, Rutter, DeLavore, \& Risi, 2001) was used to confirm ASD in the ASD group, to rule out ASD in the TD group, and to determine ASD status in the FXS group. The ADOS was also used as a continuous measure of autism symptom severity as described by Gotham, Pickles, and Lord (2009). The ADOS was administered concurrently for 36 participants with ASD, 30 with FXS, and 20 with TD. The remaining participants were administered the ADOS within one year of the time of the main assessment. Nonconcurrent ADOS data were used to confirm diagnostic status but were not included in correlational analyses in order to prevent confounds related to potential changes in symptom severity over time. The "autism spectrum" cutoffs of the revised diagnostic algorithms were used to determine the presence of ASD (Gotham et al., 2008; Gotham, Risi, Pickles, \& Lord, 2007). The ADOS was scored by examiners who met standard requirements for research reliability. Mean inter-rater reliability was calculated on a randomly selected subset (13\%) of participants, and reliability was $86 \%$ for individual items, $85 \%$ for diagnostic algorithm items, and $93 \%$ for diagnostic classification. Thirty-two of the boys with FXS met criteria for ASD.

Cognitive assessment-Nonverbal cognition was assessed with the Brief IQ Composite of the Leiter-R (Roid \& Miller, 1997). Due to time constraints, Leiter-R data were unable to be collected for seven boys with ASD, and scores from the Performance IQ scale of the Wechsler Abbreviated Scale of Intelligence (Wechsler, 1999) were used as a substitute measure of nonverbal intelligence.

Receptive and expressive language assessment-The PPVT (Dunn \& Dunn, 1997) was employed to assess receptive vocabulary. Two boys with ASD received the Peabody Picture Vocabulary Test-IV (Dunn \& Dunn, 2007). Expressive vocabulary was measured with the EVT (Williams, 1997). Age-equivalent scores for the PPVT and EVT were used in analysis. Two boys with ASD and one boy with TD were missing PPVT data; the EVT was missing for four boys with ASD and one boy with TD.

Pragmatic language assessment-The Pragmatic Judgment subtest of the Comprehensive Assessment of Spoken Language (CASL-PJ; Carrow-Woolfolk, 1999) was administered as a measure of the knowledge and use of language in social contexts. In this standardized assessment, participants answer questions about what should be said or done in various social situations. CASL-PJ scores were not collected for the TD group because this was not an aim of the larger study from which the boys were recruited. CASL-PJ scores were missing for seven participants with ASD and two participants with FXS due to time 
constraints; one participant with ASD obtained a raw score of " 0 ," and scores for this participant were considered missing. Age-equivalent scores were used in analysis.

The Pragmatic Rating Scale-School Age (PRS-SA; Landa, 2011) was administered as a semi-naturalistic measure of conversational pragmatic language abilities. The PRS-SA consists of 33 items that sample a range of pragmatic features, such as the ability to initiate topics, the provision of necessary background information, or the use of appropriate rate and volume of speech. Items are tallied to obtain a total score ranging from 0 to 66 with a higher score indicating greater impairment. The PRS-SA was scored from video, based on interaction that occurred during the ADOS. The PRS-SA was only available for those participants who had been administered the ADOS concurrently (i.e., the PRS-SA was missing for four participants with ASD, nine with FXS, and eight with TD). Five children from the ASD group and six from the FXS group were administered the ADOS module 2 (for use with individuals who have phase speech), and the remaining children were administered the ADOS module 3 (for verbally fluent individuals); there were no significant differences between the PRS-SA scores of children who had been administered module 2 versus module 3 within each group. The first author (JK), who had achieved reliability with the developer of the PRS-SA, coded all of the samples. The coder was blind to the diagnosis of $46 \%$ of the participants with ASD, 70\% with FXS, and 90\% with TD (the coder had assisted in participant assessment, and it was not possible to maintain blinding to all participants). Twenty percent of the sample was randomly selected and second-scored by a blind, independent rater who had also achieved reliability with the developer of the PRS-SA. Intraclass correlations were computed and inter-rater reliability (ICC [3, 2]) was $0.97(0.91$ for ASD, 0.91 for FXS, and 0.94 for TD).

Physiological assessment-Heart activity data were collected during a baseline resting condition and a conversational condition. During baseline, participants watched $10 \mathrm{~min}$ of an animated children's film. Movie watching was chosen as the baseline task because it was thought that the disability groups would be unable to complete a more traditional baseline task (sitting alone quietly); this approach is consistent with several other physiology studies of developmental disabilities (e.g., Hall et al., 2009; Roberts et al., 2011; Roberts et al., 2001). Immediately following the baseline period, a conversation condition took place in which participants conversed with an examiner about any topic of interest for $10 \mathrm{~min}$. In order to obtain a naturalistic sample, examiners maintained the conversation by commenting, asking questions, and bringing up topics of possible interest to the participant. No specific demands were placed on the participants other than that they remained seated and did not touch the electrodes (i.e., participants were not specifically directed to maintain eye contact or instructed to act in a certain way). Heart rate was not measured during the ADOS (the conversational sample that served as the basis for the PRS-SA) because of concerns that wearing the electrodes might influence participants' behavior in ways that could lead to invalid ASD characterization. Conversely, it was not possible to rate the PRSSA directly from the physiology conversational condition due to the brevity of the sample (the PRS-SA was developed for use with a 30-60 min conversational sample).

Electrocardiogram data was collected with an Alive Wireless Heart Monitor (Alive Technologies, Copyright 2005-2009), either via two electrodes that were placed on the participant's chest or with an elastic Polar belt that contained electrode receptors (the belt was presented as an option for participants who refused the electrodes). Data were sampled at a rate of 300 times per second. Twelve boys with FXS and three with ASD (not included in sample $n$ s) were recruited for the study, but data collection was unable to be completed due to random equipment malfunction, excessive movement/recording artifacts (>20\%), or uncooperativeness. Electrocardiogram data from the last $5.5 \mathrm{~min}$ of baseline and the first 8 min of conversation were analyzed. This portion of the baseline was selected in order to 
obtain a "pure" resting physiological estimate by allowing time for the participant to acclimate to the sensation of the electrodes. Only the first $8 \mathrm{~min}$ of the conversational condition were analyzed to ensure equal sample time across participants (occasionally, the sample ended premature of the full $10 \mathrm{~min}$ due to participant uncooperativeness). Data were edited with CardioEdit software (Brain-Body Center, University of Illinois at Chicago) by a reliable research assistant. Editing consisted of visual inspection of the electrocardiogram signal to identify invalid heart periods (e.g., faulty $\mathrm{R}$ wave detection) and manual adjustment of artifacts using integer arithmetic. Estimates for RSA and interbeat interval (IBI) were extracted. Briefly, IBI is measured as the time in milliseconds between successive R waves. To extract RSA, sequential heart periods are sampled at $250-\mathrm{ms}$ epochs, and data is detrended with a 21-point moving polynomial algorithm (Porges \& Bohrer, 1990). Data is then bandpass filtered to extract variance associated with spontaneous breathing parameters $(0.24-1.04 \mathrm{~Hz})$, and the variance is transformed to its natural logarithm to yield an estimate of RSA. The average RSA and IBI for each condition, measured from 30-s epochs, were used in analyses. Change scores, measuring reactivity, were computed by subtracting conversational estimates from baseline.

Anxiety-Symptoms of anxiety were assessed with the Child Behavior Checklist- $1 \frac{1}{2}-5$ years (CBCL; Achenbach \& Rescorla, 2000), which was completed by the primary caregiver. The Diagnostic and Statistical Manual of Mental Health Disorders-IV (DSM-IV)oriented anxiety subscale was used, and it corresponds to the diagnostic criteria for anxiety outlined in the DSM-IV (American Psychiatric Association, 1994). The preschool version of this assessment was administered as the younger items were judged to be more closely aligned with the mental ages of the study participants. Raw scores were used in analysis in accordance with the recommendations of the test publishers for use in research (Achenbach \& Rescorla, 2000). These data were missing for eight participants with ASD, 13 participants with FXS, and seven participants with TD.

\section{Data Analysis}

Group differences in IBI and RSA were tested with repeated measures analysis of covariance (ANCOVA) with condition (baseline, conversation) as a within-participants factor, controlling for chronological age. ANCOVA was also conducted to test group differences in the magnitude of IBI and RSA change, controlling for chronological age. Next, the impact of autism symptom severity on cardiac activity was explored by (a) examining the association between the cardiac indices and continuously distributed autism symptom severity (ADOS severity score) with Spearman correlations, and (b) by examining means descriptively among ASD subgroups of the FXS group. Given the limited sample size of children with FXS without comorbid ASD $(n=7)$, group differences were not tested statistically. Spearman correlations were used to examine the relationship between the six cardiac variables (IBI and RSA estimates for baseline, conversation, and change) and clinical symptoms of anxiety, and group differences in the severity of anxiety were tested with ANOVA.

Analyses were then conducted to test cardiac activity as a predictor of pragmatic language ability across groups. First, Spearman correlations were used to explore relationships between the six cardiac variables, receptive vocabulary (PPVT), expressive vocabulary (EVT), and pragmatic language (CASL-PJ and PRS-SA) within each group. These exploratory analyses were conducted in order to guide more focused analyses examining cardiac activity as a predictor of pragmatic language, given that pragmatic language ability may be influenced by receptive/expressive language skills (McTear \& Conti-Ramsden, 1992). Linear regression models were used to test cardiac activity as a predictor of pragmatic language after accounting for receptive/expressive vocabulary (PPVT and EVT). 


\section{Results}

\section{Group Differences in Cardiac Activity and the Impact of Autism}

Descriptive statistics for the physiological variables are presented in Table 2. Examination of individual patterns of physiological activity showed that 21/40 (52.5\%) of the participants with ASD, 28/39 (71.8\%) with FXS, and 15/28 (53.6\%) with TD increased RSA from baseline to conversation. Most participants decreased IBI (i.e., increased heart rate) in conversation; 82.5\% (33/40) of the participants with ASD, 82.1\% (32/39) with FXS, and 92.9\% (26/28) with TD increased heart rate during conversation.

Group differences in heart rate-Group membership had a significant main effect on IBI $\left(F[2,103]=3.42, p=.036, \eta^{2}=.06\right)$. Follow-up Bonferonni-corrected pair-wise comparisons showed that the FXS group had significantly lower IBI (i.e., faster heart rate) than the TD group $(p=.040)$ but did not differ from the ASD group $(p=.173)$. The mean IBIs of the ASD and TD groups did not differ $(p=.349)$. A main effect was detected for condition with lower IBI (i.e., faster heart rate) during conversation than at baseline ( $F[1$, $103]=4.93, p=.029, \eta^{2}=.05$ ). The interaction between group and condition was not significant $(p=.855)$, indicating that all groups showed similar increases in heart rate in response to the conversational task. The magnitude of IBI change did not differ across groups $\left(F[3,107]=0.67, p=.562, \eta^{2}=.01\right)$.

Group differences in vagal tone-The effect of the group and its interaction with condition had nonsignificant effects on RSA $(p s>.690)$. The main effect of condition approached significance $\left(F[1,103]=2.87, p=.093, \eta^{2}=.03\right)$ with a trend for higher vagal tone during the conversational condition. The magnitude of RSA change did not differ across groups $\left(F[3,107]=1.26, p=.161, \eta^{2}=.04\right)$.

Cardiac activity in ASD subgroups of FXS-Although the small number of participants with FXS without comorbid ASD (FXS-only, FXS-O) prevented group differences from being tested statistically, cardiac activity was examined descriptively across the FXS-O and FXS with comorbid ASD (FXS-ASD) groups, controlling for chronological age. Age-adjusted group means for IBI are depicted in Figure 1. Overall, IBI in the FXS-ASD subgroup was lower than that of the FXS-O group (indicating faster heart rate in the FXS-ASD group). The FXS-ASD group had the lowest mean IBI of all of the groups, and the IBI estimates of the FXS-O group were more similar to that of the ASD group.

Age-adjusted group estimates for RSA are presented in Figure 2. The boys with FXS-O had higher mean RSA in comparison with all other groups across both conditions. In contrast, the RSA of the boys with FXS-ASD was the lowest of all of the groups at baseline with a sharp increase in response to the conversation condition. During conversation, RSA of the FXS-ASD group was similar to that of the TD group.

\section{Relationship between cardiac activity and autism symptom severity-Autism} severity was not associated with any of the physiological variables in the ASD ( $p s>.286)$ or FXS ( $p s>.228)$ groups. In the TD group, continuously distributed symptoms of autism were significantly associated with RSA at baseline $(\rho=-.58, p=.007)$ and during conversation $(\rho=-.57, p=.009)$ with lower vagal tone associated with increased autism symptom severity.

Relationship between cardiac activity and symptoms of anxiety-ANOVA indicated a significant group effect for the CBCL-anxiety subscale $(F[2,76]=5.49, p=$. 
006). Bonferonni-corrected post-hoc comparisons showed that, whereas both disability groups exhibited more anxiety than the boys with TD ( $p$ s <.027), the FXS and ASD groups did not differ from each other $(p=1.00)$. No significant associations were detected between anxiety and any of the cardiac variables across groups ( $p s>.136)$. Anxiety symptoms were also not associated with either pragmatic language measures across the groups ( $p s>.092$ ).

\section{Heart Rate and Pragmatic Language Ability}

\section{Associations between heart rate and pragmatic language-Exploratory} correlations between the IBI variables and pragmatic language are presented in Table 3 . Among the boys with ASD, performance on the CASL-PJ was associated with baseline and change in IBI, indicating that pragmatic language skills got worse with higher heart rate and less increase in arousal in response to conversation. In the FXS group, a marginal association between IBI change and pragmatic language performance on the PRS-SA was detected in the opposite direction $(p=.052)$ with more substantial arousal change (i.e., greater arousal in response to the conversational condition) associated with worse pragmatic language skills. In the boys with TD, no significant correlations were observed between the IBI and pragmatic language variables although a trend-level association between conversational IBI and pragmatic performance on the PRS-SA was detected $(p=.073)$ with greater arousal during conversation linked with worse pragmatic skills.

Exploratory correlations between IBI and expressive and receptive vocabulary are presented in Table 3 in order to inform specific associations with pragmatics language versus general language skills. In the ASD group, IBI change was significantly associated with performance on the EVT with less change in arousal corresponding to worse expressive vocabulary skills. No other significant associations were detected with receptive/expressive vocabulary.

Heart rate as a predictor of pragmatic language-Significant correlations were followed up with more specific analyses testing heart rate as a predictor of pragmatic language skills after controlling for receptive/expressive vocabulary. First, baseline IBI was tested as a unique predictor of CASL-PJ performance in the ASD group; after accounting for the variance associated with receptive and expressive vocabulary, baseline IBI did not account for significant additional variance in the CASL-PJ $\left(R^{2}=.88, R^{2} \Delta=.01, F \Delta[1,26]\right.$ $=0.87, p=.360$ ). IBI change was also not a significant predictor of CASL-PJ performance after accounting for receptive/expressive vocabulary in $\operatorname{ASD}\left(R^{2}=.87, R^{2} \Delta=.01, F \Delta[1\right.$, $24]=0.01, p=.971)$.

\section{Vagal Tone and Pragmatic Language Ability}

Associations between vagal tone and pragmatic language-In ASD, baseline RSA was associated with the CASL-PJ with lower vagal tone linked with poorer pragmatic performance. A significant association between dampened RSA during conversation and worse pragmatic skills on the PRS-SA was also detected in ASD (along with a trend-level association in the same direction with pragmatics on the CASL-PJ, $p=.061$ ). In the FXS group, RSA change was negatively associated with CASL-PJ performance, indicating that the boys with FXS who showed less vagal change from the baseline to the conversational task had worse performance on the standardized measure of pragmatic language. No other significant correlations were detected between the RSA variables and pragmatics although a marginal association was detected in the TD group between RSA change and the PRS-SA ( $p$ $=.097)$. Correlations are presented in Table 3 .

Exploratory associations between RSA and receptive and expressive vocabulary showed a negative relationship between RSA change and performance on the EVT and PPVT in the 
FXS group (consistent with worse vocabulary skills as the boys showed less vagal reactivity). No other significant associations were observed with receptive/expressive vocabulary.

Vagal activity as a predictor of pragmatic language—Linear regression was used to test conversational RSA as a predictor of PRS-SA performance in ASD; results indicated that RSA during conversation accounted for a significant proportion of variance in PRS-SA scores $(11 \%)$, even after accounting for receptive and expressive vocabulary $\left(R^{2}=.36, R^{2} \Delta\right.$ $=.11, F \Delta[1,30]=5.04, p=.032$ ). A second regression was run to test baseline RSA as a predictor of CASL-PJ scores in ASD; after accounting for receptive/expressive vocabulary skills, baseline RSA was not a significant predictor of pragmatic performance on the CASL$\mathrm{PJ}$ in $\operatorname{ASD}\left(R^{2}=.88, R^{2} \Delta<.01, F \Delta[1,26]=0.16, p=.697\right)$.

Next, RSA change was tested as a predictor of pragmatic language on the CASL-PJ among the boys with FXS. Results showed that the combined influence of receptive/expressive vocabulary accounted for significant variance in the CASL-PJ scores in FXS $\left(R^{2}=.69, F \Delta\right.$ $[2,34]=37.97, p<.001)$, but the addition of RSA change to the model did not account for significant variance above and beyond receptive/expressive vocabulary $\left(R^{2}=.69, R^{2} \Delta=.01\right.$, $F \Delta[1,33]=0.01, p=.925)$.

\section{Discussion}

This study examined cardiac arousal and parasympathetic activity as potential neurobiological markers of pragmatic language difficulties in boys with ASD, FXS, and TD. Boys with ASD and FXS showed similar physiological profiles, including similar levels of general arousal and vagal tone at rest and during conversion with an examiner. The boys with FXS were hyperaroused in comparison to the boys with TD, but their general arousal level did not differ from the boys with ASD. The arousal level of the ASD group was moderately elevated but did not differ significantly from either the FXS or TD groups. Vagal tone did not differ across groups, suggesting that parasympathetic nervous system functioning was similar across groups. Furthermore, boys with ASD and FXS showed physiological responses that were similar to those of boys with TD in response to the conversational task, indicating that conversation did not elicit atypically elevated levels of arousal in either the ASD or FXS groups. Dampened vagal tone during conversation predicted impaired pragmatic language performance in ASD even after accounting for variation in receptive and expressive vocabulary skills. Together, these findings add to emerging evidence for a role of autonomic nervous system dysfunction in pragmatic language impairment in ASD. Results also have implications for understanding biophysiological pathways that may be shared in ASD and FXS and which may be linked to FMRI-related genetic effects.

\section{Group Differences in Physiological Profiles}

To our knowledge, this is the first report to directly compare cardiac indices of arousal in ASD and FXS. As a single-gene disorder that is associated with significantly elevated risk for ASD, FXS may be a useful model for reducing "genetic noise" to speed the identification of pathophysiological mechanisms implicated in ASD. In the present study, the physiological profiles of FXS did not differ from those of ASD, suggesting that biophysiological pathways that are disrupted in FXS may also be common to idiopathic ASD and, providing support for FMRl, the FXS gene as a potential candidate gene for ASD. While a body of research supports phenotypic overlap in idiopathic ASD and FXSassociated ASD (Bailey et al., 1998; Dissanayake et al., 2009; Rogers et al., 2001), the results of the present study contribute new evidence to support shared biophysiological 
characteristics in these disorders. Specifically, the boys with ASD and the boys with FXS did not differ on measures of general arousal or vagal tone in either condition examined. The study of the autonomic nervous system as an intermediate biological process that may be dysregulated in both FXS and ASD may help bridge the gap between behavior and genes; current genetic models suggest that FMR1 may lead to the ASD phenotype through its interaction with other "background" genes, thereby lowering the genetic threshold needed to produce ASD (Bailey, Hatton, Skinner, \& Mesibov, 2001; Harris et al., 2008; Rogers et al., 2001). Given that biological mechanisms are more directly linked with underlying genetic effects than are behavioral symptoms, identifying biophysiological pathways that are common to ASD and FXS may help uncover molecular/genetic mechanisms that interact with FMRI to produce the ASD phenotype.

While the arousal levels of the boys with ASD and FXS did not differ from each other, only the boys with FXS showed significantly elevated arousal in comparison to the boys with TD. Descriptively, the boys with ASD showed arousal levels that were lower on average than that of the FXS group but higher on average than those of the TD boys (with neither difference statistically significant). There is great inconsistency across prior investigations of arousal in ASD with a number of reports indicating that heart rate in ASD is similar to controls (Althaus et al., 1999; Corona et al., 1998; MacCulloch \& Williams, 1971; Sigman et al., 2003) and other reports suggesting that heart rate is atypically elevated (Bal et al., 2010; Goodwin et al., 2006; Mathewson et al., 2011; Woodard et al., 2012). The inconsistency across studies might suggest that elevated heart rate is only characteristic of particular subgroups of individuals with ASD, which is consistent with the "middle of the road" arousal level detected in this study. Even if arousal modulation dysfunction is evident only in a subgroup of individuals with ASD, physiological regulatory difficulties may serve as a useful marker for identifying homogeneous subgroups of ASD, helping to uncover biological systems that may respond to targeted pharmaceutical or behavioral treatments. Additional research investigating arousal modulation as a potential endophenotype (i.e., a marker of genetic susceptibility) for ASD might prove useful as measures of cardiovascular activity are noninvasive, reliable, quantitative indices that tap biologically meaningful functions that may be more closely tied to underlying genetic variation than clinical phenotypes.

The finding of elevated heart rate in FXS is consistent with a body of prior reports documenting hyperarousal in FXS (Hall et al., 2009; Heilman et al., 2011; Roberts et al., 2001; Roberts et al., 2012). Furthermore, the results of this study suggest that hyperarousal is a chronic physiological condition in FXS as heart rate was consistently elevated across both experimental conditions. Given that the parasympathetic vagal tone of the FXS group was similar to the TD boys, it may be that the elevated heart rate in FXS was driven by increased sympathetic tone. This interpretation is consistent with evidence from skin conductance studies showing elevated sympathetic tone in FXS (Miller et al., 1999; Roberts, Mazzocco, Murphy, \& Hoehn-Saric, 2008). While this study cannot directly address this hypothesis, future research might include measures of both parasympathetic and sympathetic tone to pinpoint specific areas of breakdown in the autonomic system in FXS.

Contrary to hypotheses, vagal tone in the FXS and ASD groups did not differ from that of the boys with TD. A number of prior reports have documented dampened vagal tone in FXS (Boccia \& Roberts, 2000; Hall et al., 2009; Heilman et al., 2011; Roberts et al., 2001;

Roberts, Boccia, Hatton, Skinner, \& Sideris, 2006) whereas findings from previous studies of ASD are mixed with reports that vagal tone is either reduced (Bal et al., 2010; Ming et al., 2005; Van Hecke et al., 2009) or similar to controls (Althaus et al., 1999; Toichi \& Kamio, 2003; Watson, Roberts, Baranek, Mandulak, \& Dalton, 2012). The mean vagal estimates detected in this study are consistent with prior reports: At baseline, the boys with FXS 
showed vagal tone that was lower on average than the ASD and TD groups, who were similar to each other. It is possible that this study was underpowered to detect group effects. The sample characteristics of the present study may have also influenced findings; nonverbal children were excluded from the study, and perhaps this subgroup displays a distinct physiological profile from higher functioning verbal children. Additionally, there exists considerable variation in the methods employed in prior studies of physiology in ASD and FXS. In this study, unlike others (e.g., Heilman et al., 2011), cardiac activity was sampled after several hours of working with the examiner, possibly allowing the participants to become more comfortable (and less physiologically defensive) than if cardiac activity had been sampled earlier. It will be important to study directly the influence of familiarity with conversational partners on physiological arousal in future studies.

\section{Physiological Activity as a Predictor of Pragmatic Language}

A main finding of this work is that parasympathetic tone during conversation predicted pragmatic language skill in ASD even after accounting for receptive and expressive vocabulary. It is interesting that pragmatic language was specifically related to vagal tone in the conversational context but not at baseline. This finding is similar to that of Watson et al. (2010), who found that vagal tone during a social context (but not while watching a nonsocial video) accounted for significant variance in parent-reported social-communication outcomes of young children with ASD. As suggested by Watson et al. (2010), children with ASD who show higher vagal tone in social contexts may present with a physiological state that is more optimal for engaging with social stimuli. Consistent with transactional theories of social learning, increased social engagement is thought to lead to greater opportunities for social learning over time, including the learning of pragmatic conversational rules (Chapman, 2000; Dickinson \& McCabe, 1991). Perhaps resting vagal tone was not related to pragmatic language outcomes because social learning might depend specifically on the ability to make physiological adjustments to adapt to social demands.

The identification of neurophysiological markers associated with social dysfunction in ASD has implications for the development of interventions targeted at correcting breakdowns at the physiological level. Vagal tone appears to respond to noninvasive treatments, such as massage therapy or breathing exercises, in typical development (Chambers \& Allen, 2002; Feldman \& Eidelman, 2003; Lee, 2005; Miu, Heilman, \& Miclea, 2009), and some evidence suggests that pharmaceutical intervention may improve arousal modulation in FXS (Roberts et al., 2011). The results of this study support the investigation of treatments targeting autonomic dysfunction as a means to improve communication outcomes in ASD.

It is unclear why physiological profiles predicted pragmatic language outcomes in the ASD group but not in the FXS group. When considering marginal associations, some differential patterns begin to emerge across groups with more significant heart-rate change associated with better pragmatic skills in the ASD group and worse pragmatic skills in the FXS group. Given that baseline arousal of the groups differed, it is possible that the groups relied on different regulatory processes to achieve an optimal arousal level; while the ability to increase arousal assisted the children with ASD in meeting task demands, it appears that additional increases in arousal did not improve the performance of the already hyperaroused FXS group. Although cardiac activity did not independently predict pragmatic language skills in the FXS group, several associations were detected with receptive and expressive vocabulary skills, suggesting that physiological modulation does play a role in communication abilities in FXS. Future research investigating potential interacting factors, such as cognition, anxiety, and executive abilities, might clarify the role of physiological activity in the pragmatic language performance of individuals with FXS. 


\section{Conversation as an Elicitor of Arousal in ASD and FXS}

A notable finding was that unstructured conversation with an examiner did not result in atypically elevated arousal in either ASD or FXS. While the boys with ASD and FXS did increase arousal in response to conversation, this appeared to be a typical response given that increases of a similar magnitude were observed in the TD group. Hall et al. (2009) also found that boys with FXS showed increased heart rate in response to a conversational task, which was similar to the increases that were observed in their TD siblings. Evidence that conversation does not elicit hyperarousal in ASD and FXS might imply that atypical social behaviors of these disorders are not related to socially induced hyperarousal—at least during unstructured conversation with an examiner. Clinically, these findings suggest that clinicians working with children with ASD or FXS need not be wary of engaging with the child in fear of causing the child to become overly aroused. This finding does not, however, preclude a relationship between general physiological health and social engagement; it merely implies that social interaction itself does not appear to be a catalyst for hyperarousal.

\section{Autism Severity and Physiological Activity}

A remaining question is why autism severity was associated with physiological activity in TD but not within ASD or FXS as the parasympathetic nervous system is thought to set the stage for social engagement, which is a core deficit in ASD and FXS. The robust correlations detected in the TD group are somewhat unexpected given the limited range of ADOS severity scores in the TD group (by definition, participants with TD had subclinical ADOS severity scores that ranged from one to four points). Other studies have also failed to detect a relationship between heart rate/vagal tone and autism severity among children with idiopathic ASD (Jansen, Gispen-de Wied, van der Gaag, \& van Engeland, 2003; Patriquin et al., 2011; Van Hecke et al., 2009). With regards to FXS, a recent report by Roberts et al. (2012) did find that vagal tone and autism severity were associated in young toddlers with FXS. In the present study of older children with FXS, such a relationship was not observed although associations followed the same direction. More research is needed to clarify developmental changes in vagal activity over time and whether associations between vagal activity and behavior are most prominent during specific developmental stages. Although this study did not detect a relationship between cardiac activity and general symptoms of ASD, physiological modulation was linked to communication difficulties that represent a subdomain of the ASD phenotype. This area of research warrants further attention as understanding how independent biophysiological mechanisms may lead to the presentation of ASD (or to the presentation of subdomains of ASD) will be informative for the development of interventions targeting these pathways.

\section{Links With Anxiety}

In studies of FXS, anxiety is often hypothesized to be rooted in hyperarousal (e.g., Sudhalter $\&$ Belser, 2001). However, the few studies that have tested this hypothesis empirically have failed to detect a relationship between anxiety and cardiac arousal in FXS (Keysor, Mazzocco, McLeod, \& Hoehn-Saric, 2002) and ASD (Jansen et al., 2006; Mathewson et al., 2011) as well as in individuals with anxiety disorders (Kelly, Brown, \& Shaffer, 1970; McLeod, Hoehn-Saric, Zimmerli, de Souza, \& Oliver, 1990; Tyrer \& Alexander, 1980). The results of this study are consistent with these prior reports; cardiac activity was not associated with parent-reported symptoms of anxiety in any group. It is notable, however, that the ASD and FXS groups did not differ on parent-reported symptoms of anxiety, suggesting that the syndrome-specific associations between physiological activity and pragmatic language were not driven by group differences in anxiety level. Given that anxiety affects a significant proportion of individuals with ASD and FXS (Cordeiro, Ballinger, Hagerman, \& Hessl, 2011; Merenstein et al., 1996; van Steensel, Bögels, \& 
Perrin, 2011; White, Oswald, Ollendick, \& Scahill, 2009), further exploration of the role of anxiety (and its interaction with physiological arousal) in behavioral outcomes may be useful for honing treatments in these populations.

\section{Directions and Limitations}

Several limitations of the study should be considered in interpreting results. First, the mean chronological ages of the groups differed (a confound for which we controlled statistically). Second, although the sample was relatively large in comparison to other studies of FXS, we may nonetheless lack statistical power to detect group differences. Third, the physiological responses observed in this study may be the most representative of those boys with FXS who have comorbid ASD given that the majority of the boys with FXS in this study met diagnostic criteria for ASD. The small participant numbers of children with FXS without ASD also prevented formal examination of the impact of ASD status on the physiological responses of individuals with FXS, which would be informative in understanding the biophysiological underpinnings of ASD in FXS. The sample of this study also consisted of children who were able to use phrase speech (so that participants could complete the conversational task of interest), which may limit generalizability to nonverbal individuals. Additionally, a number of children from the FXS and ASD groups were taking psychoactive medications, which may influence heart activity, depending on individual dosage and physical characteristics, such as weight and metabolic functioning (O'Brien \& Oyebode, 2003; Rechlin, 1995; Silke, Campbell, \& King, 2002). However, we felt it was important to include children who were taking medications to improve external validity as 50\%-75\% of children with ASD and FXS use psychotropic medications (Mandell et al., 2008; Morgan, Roy, \& Chance, 2003; Valdovinos, Parsa, \& Alexander, 2009). Finally, the design of the current work can only shed light on how cardiac activity during one conversational condition predicts pragmatic performance in a different social-communicative context (it was not possible to collect pragmatic and physiological data from the same conversational sample, see Methods). Future work might sample cardiac activity and pragmatic language concurrently in order to clarify context-specific relationships. Future studies would also benefit from assessments at different developmental periods and from following children longitudinally to understand how physiological characteristics may be related to language outcomes across time, thus enhancing understanding of physiological underpinnings of social language in ASD and FXS and providing insights into developmental periods that could be most responsive to intervention.

\section{Acknowledgments}

This paper was completed as part of the first author's doctoral dissertation, which was supported in part by the James J. Gallagher Dissertation Award of Frank Porter Graham Child Development Institute. This work was funded by the National Institute of Child Health and Human Development (R01HD0388190-62A, R01HD038819-09S1, R01HD044935-06A), the National Institute on Deafness and Other Communication Disorders (1R01DC010191-01A1, R03DC010880), the National Institute of Mental Health (R01MH091131-01A1), the National Fragile X Foundation, the Ireland Family Foundation, and the Research Participant Registry Core of the Carolina Institute for Developmental Disabilities (P30HD03110). The authors would like to thank Linda Watson, Heather Cody Hazlett, and Jane Roberts for their comments on an earlier version of this manuscript, Abigail Hogan-Brown for her assistance with the pragmatic language coding and John Sideris for his guidance on the statistical analyses. We also thank Rebecca Landa for permitting our use of the Pragmatic Rating Scale-School Age in this project, and for providing training and guidance on its implementation. We gratefully acknowledge the late Dr. Joanne Roberts, who was awarded the original NICHD grants that supported the initial phases of this research, and the children and families who participated. 


\section{References}

Abbeduto L, Murphy MM, Kover ST, Karadottir S, Amman A, Bruno L. Signaling noncomprehension of language: A comparison of fragile $\mathrm{X}$ syndrome and Down syndrome. American Journal on Mental Retardation. 2008; 113:214-230. [PubMed: 18407723]

Abrahams BS, Geschwind DH. Advances in autism genetics: On the threshold of a new neurobiology. Nature Reviews: Genetics. 2008; 9:341-355.

Achenbach, TM.; Rescorla, LA. Manual for the ASEBA preschool forms and profiles. Burlington, VT: University of Vermont Department of Psychiatry; 2000.

Adams C, Green J, Gilchrist A, Cox A. Conversational behaviour of children with Asperger syndrome and conduct disorder. Journal of Child Psychology and Psychiatry, and Allied Disciplines. 2002; 43(5):679-690.

Alive Technologies. (Copyright 2005-2009). Alive Heart Monitor: Bluetooth ECG and Activity Monitor. Alive Technologies Pty Ltd;

Alkon A, Goldstein LH, Smider N, Essex MJ, Kupfer DJ, Boyce WT. Developmental and contextual influences on autonomic reactivity in young children. Developmental Psychobiology. 2003; 42(1): 64-78. [PubMed: 12471637]

Althaus M, Mulder LJM, Mulder G, Aarnoudse CC, Minderaa RB. Cardiac adaptivity to attentiondemanding tasks in children with a pervasive developmental disorder not otherwise specified (PDDNOS). Biological Psychiatry. 1999; 46(6):799-809. [PubMed: 10494448]

American Psychiatric Association.. Diagnostic and statistical manual of mental disorders. 4. Washington, DC: Author; 1994.

American Psychiatric Association.. Diagnostic and statistical manual of mental disorders. 5. Washington, DC: Author; 2013.

Bailey DB, Hatton DD, Skinner M, Mesibov G. Autistic behavior, FMR1 protein, and developmental trajectories in young males with Fragile X syndrome. Journal of Autism and Developmental Disorders. 2001; 31(2):165-174. [PubMed: 11450815]

Bailey DB, Mesibov G, Hatton DD, Clark RD, Roberts JE, Mayhew L. Autistic behavior in young boys with fragile X syndrome. Journal of Autism and Developmental Disorders. 1998; 28(6):499508. [PubMed: 9932236]

Bal E, Harden E, Lamb D, Vaughan Van Hecke A, Denver JW, Porges SW. Emotion recognition in children with autism spectrum disorders: Relation to eye gaze and autonomic state. Journal of Autism and Developmental Disorders. 2010; 40:358-370. [PubMed: 19885725]

Bar-Haim Y, Marshall PJ, Fox NA. Developmental changes in heart period and high-frequency heart period variability from 4 months to 4 years of age. Developmental Psychobiology. 2000; 37(1): 44-56. [PubMed: 10937660]

Bates, E. Language in context. New York: Academic Press; 1976.

Baumgardner TL, Reiss AL, Freund LS, Abrams MT. Specification of the neurobehavioral phenotype in males with fragile X syndrome. Pediatrics. 1995; 95(5):744-752. [PubMed: 7724315]

Belser RC, Sudhalter V. Arousal difficulties in males with fragile X syndrome: A preliminary report. Developmental Brain Dysfunction. 1995; 8(4):270-279.

Belser RC, Sudhalter V. Conversational characteristics of children with fragile X syndrome: Repetitive speech. American Journal on Mental Retardation. 2001; 106(1):28-38. [PubMed: 11246710]

Betancur C. Etiological heterogeneity in autism spectrum disorders: More than 100 genetic and genomic disorders and still counting. Brain Research. 2011; 1380:42-77. [PubMed: 21129364]

Blair C, Peters R. Physiological and neurocognitive correlates of adaptive behavior in preschool among children in Head Start. Developmental Neuropsychology. 2003; 24(1):479-497. [PubMed: 12850755]

Boccia ML, Roberts JE. Behavior and autonomic nervous system function as assessed via heart activity: The case of hyperarousal in boys with fragile X syndrome. Behavior Research Methods, Instruments, and Computers. 2000; 32(1):5-10.

Calkins SD, Keane SP. Cardiac vagal regulation across the preschool period: Stability, continuity, and implications for childhood adjustment. Developmental Psychobiology. 2004; 45(3):101-112. [PubMed: 15505799] 
Capps L, Kehres J, Sigman M. Conversational abilities among children with autism and developmental delay. Autism. 1998; 2:325-344.

Capps L, Losh M, Thurber C. The frog ate a bug and made his mouth sad: Narrative competence in children with autism. Journal of Abnormal Child Psychology. 2000; 28:193-204. [PubMed: 10834770]

Carrow-Woolfolk, E. CASL: Comprehensive assessment of spoken language. Circle Pines, MN: American Guidance Services; 1999.

CDC. Prevalence of autism spectrum disorders-Autism and Developmental Disabilities Monitoring Network, 14 sites, United States, 2008. Morbidity and Mortality Weekly Report: Surveillance Summaries. 2012; 61:1-19.

Chambers AS, Allen JJ. Vagal tone as an indicator of treatment response in major depression. Psychophysiology. 2002; 39:861-864. [PubMed: 12462513]

Chapman RS. Children's language learning: An interactionist perspective. Journal of Child Psychology and Psychiatry. 2000; 41(1):33-54. [PubMed: 10763675]

Cohen D, Pichard N, Tordjman S. Specific genetic disorders and autism: Clinical contribution towards their identification. Journal of Autism and Developmental Disorders. 2005; 35(1):103. [PubMed: 15796126]

Cohen IL. A theoretical analysis of the role of hyperarousal in the learning and behavior of fragile X males. Mental Retardation and Developmental Disabilities Research Reviews. 1995; 1(4):286291.

Cordeiro L, Ballinger E, Hagerman R, Hessl D. Clinical assessment of DSM-IV anxiety disorders in fragile X syndrome: Prevalence and characterization. Journal of Neurodevelopmental Disorders. 2011; 3:57-67. [PubMed: 21475730]

Corona R, Dissanayake C, Arbelle S, Wellington P, Sigman M. Is affect aversive to young children with autism? Behavioral and cardiac responses to experimenter distress. Child Development. 1998; 69(6):1494-1502. [PubMed: 9914635]

Darnell JC, Klann E. The translation of translational control by FMRP: Therapeutic targets for FXS. Nature Neuroscience. 201310.1038/nn.3379

Darnell JC, Van Driesche SJ, Zhang C, Hung KY, Mele A, Fraser CE, Darnell RB. FMRP stalls ribosomal translocation on mRNAs linked to synaptic function and autism. Cell. 2011; 146(2): 247-261. [PubMed: 21784246]

Dawson, G.; Lewy, A. Arousal, attention, and the socioemotional impairments of individuals with autism. In: Dawson, G., editor. Autism: Nature, diagnosis, and treatment. New York: Guilford Press; 1989. p. 49-74.

Devlin B, Scherer SW. Genetic architecture in autism spectrum disorder. Current Opinion in Genetics \& Development. 2012; 22(3):229-237.10.1016/j.gde.2012.03.002 [PubMed: 22463983]

Dickinson, D.; McCabe, A. The acquisition and development of language: A social interactionist account of language and literacy development. In: Kavanagh, JF., editor. The language continuum: From infancy to literacy. Communicating by language. Vol. 13. Parkton, MD: York Press; 1991. p. 1-40.

Diehl JJ, Bennetto L, Young EC. Story recall and narrative coherence of high-functioning children with autism spectrum disorders. Journal of Abnormal Child Psychology. 2006; 34(1):83-98.

Dissanayake C, Bui Q, Bulhak-Paterson D, Huggins R, Loesch DZ. Behavioural and cognitive phenotypes in idiopathic autism versus autism associated with fragile $X$ syndrome. Journal of Child Psychology and Psychiatry. 2009; 50(3):290-299. [PubMed: 19175809]

Dunn, LM.; Dunn, DM. Peabody Picture Vocabulary Test. Circle Pines, MN: American Guidance Service; 1997.

Dunn, LM.; Dunn, DM. Peabody Picture Vocabulary Test, Fourth Edition. San Antonio, TX: Pearson Assessments; 2007.

Feldman R, Eidelman AI. Skin-to-skin contact (Kangaroo Care) accelerates autonomic and neurobehavioural maturation in preterm infants. Developmental Medicine \& Child Neurology. 2003; 45(4):274-281. [PubMed: 12647930]

Geller E. An investigation of communication breakdowns and repairs in verbal autistic children. British Journal of Developmental Disabilties. 1998; 44:71-85. 
Ghaziuddin M, Leonore G. Pedantic speaking style differentiates asperger syndrome from highfunctioning autism. Journal of Autism and Developmental Disorders. 1996; 26:585-595. [PubMed: 8986845]

Goodwin MS, Groden J, Velicer WF, Lipsitt LP, Baron MG, Hofmann SG, Groden G. Cardiovascular arousal in individuals with autism. Focus on Autism and Other Developmental Disabilities. 2006; 21(2):100-123.

Gotham K, Pickles A, Lord C. Standardizing ADOS scores for a measure of severity in autism spectrum disorders. Journal of Autism and Developmental Disorders. 2009; 39:693-705. [PubMed: 19082876]

Gotham K, Risi S, Dawson G, Tager-Flusberg H, Joseph R, Carter A, Lord C. A replication of the Autism Diagnostic Observation Schedule (ADOS) revised algorithms. Journal of the America Academy of Child and Adolescent Psychiatry. 2008; 47(6):642-651.

Gotham K, Risi S, Pickles A, Lord C. The Autism Diagnostic Observation Schedule: Revised algorithms for improved diagnostic validity. Journal of Autism and Developmental Disorders. 2007; 37(4):613-627. [PubMed: 17180459]

Hagerman, R. The physical and behavioral phenotype. In: Hagerman, RJ.; Hagerman, PJ., editors. Fragile X syndrome: Diagnosis, treatment, and research. 3. Baltimore: Johns Hopkins University Press; 2002. p. 3-87.

Hagerman, R. Physical and behavioural phenotype. In: Dew-Hughes, D., editor. Educating children with fragile X syndrome: A multi-professional view. London: Routledge; 2004.

Hagerman R, Au J, Hagerman P. FMR1 premutation and full mutation molecular mechanisms related to autism. Journal of Neurodevelopmental Disorders. 2011; 3:211-224. [PubMed: 21617890]

Hagerman, R.; Hagerman, P., editors. Fragile X syndrome: Diagnosis, treatment, and research. 3. Baltimore: Johns Hopkins University Press; 2002.

Hagerman R, Hoem G, Hagerman P. Fragile X and autism: Intertwined at the molecular level leading to targeted treatments. Molecular Autism. 2010; 1(1):12. [PubMed: 20858229]

Hagerman RJ, Jackson AW, Levitas A, Rimland B, Braden M, Opitz JM, Reynolds JF. An analysis of autism in fifty males with the fragile X syndrome. American Journal of Medical Genetics. 1986; 23(1-2):359-374. [PubMed: 3953654]

Hall SS, Lightbody AA, Huffman LC, Lazzeroni LC, Reiss AL. Physiological correlates of social avoidance behavior in children and adolsecents with fragile $\mathrm{X}$ syndrome. Journal of the American Academy of Child and Adolescent Psychiatry. 2009; 48(3):320-329. [PubMed: 19182690]

Hall SS, Lightbody AA, Reiss AL. Compulsive, self-injurious, and autistic behavior in children and adolescents with fragile X syndrome. American Journal of Mental Retardation. 2008; 113(1):4453. [PubMed: 18173299]

Harris SW, Hessl D, Goodlin-Jones BL, Ferranti J, Bacalman S, Barbato I, Abbeduto L. Autism profiles of males with fragile X syndrome. American Journal on Mental Retardation. 2008; 113(6): 427-438. [PubMed: 19127654]

Heilman KJ, Bal E, Bazhenova OV, Sorokin Y, Perlman SB, Hanley MC, Porges SW. Physiological responses to social and physical challenges in children: Quantifying mechanisms supporting social engagement and mobilization behaviors. Developmental Psychobiology. 2008; 50(2):171-182. [PubMed: 18286584]

Heilman KJ, Harden ER, Zageris DM, Berry-Kravitz E, Porges SW. Autonomic regulation in fragile X syndrome. Developmental Psychobiology. 2011; 53:785-795. [PubMed: 21547900]

Iossifov I, Ronemus M, Levy D, Wang Z, Hakker I, Rosenbaum J, Wigler M. De Novo gene disruptions in children on the autistic spectrum. Neuron. 2012; 74(2):285-299. [PubMed: 22542183]

Jansen L, Gispen-de Wied C, Wiegant V, Westenberg H, Lahuis B, van Engeland H. Autonomic and neuroendocrine responses to a psychosocial stressor in adults with autistic spectrum disorder. Journal of Autism and Developmental Disorders. 2006; 36(7):891-899.10.1007/s10803-006-0124z [PubMed: 16865550]

Jansen LMC, Gispen-de Wied CC, van der Gaag RJ, van Engeland H. Differentiation between autism and multiple complex developmental disorder in response to psychosocial stress. Neuropsychopharmacology. 2003; 28(3):582-590. [PubMed: 12629541] 
Kelly D, Brown CC, Shaffer JW. A comparison of physiological and psychological measurements of anxious patients and normal controls. Psychophysiology. 1970; 6:429-441. [PubMed: 5418810]

Keysor CS, Mazzocco MM, McLeod DR, Hoehn-Saric R. Physiological arousal in females with fragile X or Turner syndrome. Developmental Psychobiology. 2002; 41(2):133-146. [PubMed: 12209655]

Klusek J, Losh M, Martin GE. Sex differences and within-family associations in the broad autism phenotype. Autism: International Journal of Research and Practice. 2012 Advance online publication. 10.1177/1362361312464529

Kok BE, Fredrickson BL. Upward spirals of the heart: Autonomic flexibility, as indexed by vagal tone, reciprocally and prospectively predicts positive emotions and social connectedness. Biological Psychology. 2010; 85(3):432-436. [PubMed: 20851735]

Landa, R. Social language use in Asperger syndrome and high-functioning autism. In: Ami, K.; Volkmar, F.; Sparrow, SS., editors. Asperger Syndrome. New York: Guilford Press; 2000. p. 403-417.

Landa, R. Rating scale. Baltimore: 2011. Pragmatic Rating Scale for School-Age Children.

Landa R, Piven J, Wzorek MM, Gayle JO, Chase GA, Folstein SE. Social language use in parents of autistic individuals. Psychological Medicine. 1992; 22(1):245-254. [PubMed: 1574562]

Lee HK. The effect of infant massage on weight gain, physiological and behavioral responses in premature infants. Taehan Kanho Hakhoe Chi. 2005; 35:1452-1460.

Levine TP, Sheinkopf SJ, Pescosolido M, Rodino A, Elia G, Lester B. Physiologic arousal to social stress in children with autism spectrum disorders: A pilot study. Research in Autism Spectrum Disorders. 2012; 6(1):177-183. [PubMed: 22081773]

Lord, C.; Rutter, M.; DeLavore, PC.; Risi, S. Autism Diagnostic Observation Schedule. Los Angeles: Western Psychological Services; 2001.

Losh M, Capps L. Narrative ability in high-functioning children with autism or Asperger's syndrome. Journal of Autism and Developmental Disorders. 2003; 33(3):239-251. [PubMed: 12908827]

Losh M, Childress D, Lam K, Piven J. Defining key features of the broad autism phenotype: A comparison across parents of multiple- and single-incidence autism families. American Journal of Medical Genetics Part B: Neuropsychiatric Genetics. 2008; 147B(4):424-433.

Losh M, Klusek J, Martin GE, Sideris J, Parlier M, Piven J. Defining genetically meaningful language and personality traits in relatives of individuals with fragile $\mathrm{X}$ syndrome and relatives of individuals with autism. American Journal of Medical Genetics Part B: Neuropsychiatric Genetics. 2012; 159B:660-668.

Losh M, Martin GE, Klusek J, Hogan-Brown AL, Sideris J. Social communication and theory of mind in boys with autism and fragile X syndrome. Frontiers in Psychology. 2012; 3:1-12. [PubMed: 22279440]

Loveland KA, McEvoy RE, Tunali B. Narrative story telling in autism and Down's syndrome. British Journal of Developmental Psychology. 1990; 8:9-23.

MacCulloch MJ, Williams C. On the nature of infantile autism. Acta Psychiatrica Scandinavica. 1971; 47(3):295-314. [PubMed: 5142571]

Mandell DS, Morales KH, Marcus SC, Stahmer AC, Doshi J, Polsky DE. Psychotropic medication use among medicaid-enrolled children with autism spectrum disorders. Pediatrics. 2008; 121(3):441448.

Martin GE, Roberts JE, Helm-Estabrooks N, Sideris J, Vanderbilt J, Moskiwitz L. Perseveration in the connected speech of boys with fragile $\mathrm{X}$ syndrome with and without autism spectrum disorder. American Journal on Intellectual and Developmental Disabilities. 2012; 117(5):384-399. [PubMed: 22998486]

Martin I, McDonald S. Weak coherence, no theory of mind, or executive dysfunction? Solving the puzzle of pragmatic language disorders. Brain and Language. 2003; 85(3):451-466. [PubMed: 12744957]

Mathewson KJ, Drmic IE, Jetha MK, Bryson SE, Goldberg JO, Hall GB, Schmidt LA. Behavioral and cardiac responses to emotional stroop in adults with autism spectrum disorders: Influence of medication. Autism Research. 2011; 4(2):98-108.10.1002/aur.176 [PubMed: 21360828] 
McDuffie A, Abbeduto L, Lewis P, Kover S, Kim J, Weber A, Brown WT. Autism spectrum disorder in children and adolescents with fragile X syndrome: Within-syndrome differences and age-related changes. American Journal of Autism and Developmental Disorders. 2010; 115(5):307-326.

McLeod DR, Hoehn-Saric R, Zimmerli WD, de Souza EB, Oliver LK. Treatment effects of alprazolam and imipramine: Physiological versus subjective changes in patients with generalized anxiety disorder. Biological Psychiatry. 1990; 28:849-861. [PubMed: 2268689]

McTear, M.; Conti-Ramsden, G. Pragmatic disability in children. London: Whurr; 1992.

Merenstein SA, Sobesky WE, Taylor AK, Riddle JE, Tran HX, Hagerman RJ. Molecular-clinical correlations in males with an expanded FMR1 mutation. American Journal of Medical Genetics. 1996; 64(2):388-394. [PubMed: 8844089]

Miller LJ, McIntosh DN, McGrath J, Shyu V, Lampe M, Taylor AK, Hagerman RJ. Electrodermal responses to sensory stimuli in individuals with fragile $\mathrm{X}$ syndrome: A preliminary report. American Journal of Medical Genetics. 1999; 83:268-279. [PubMed: 10208160]

Ming X, Julu PO, Brimacombe M, Connor S, Daniels ML. Reduced cardiac parasympathetic activity in children with autism. Brain and Development. 2005; 27:509-516. [PubMed: 16198209]

Miu AC, Heilman RM, Miclea M. Reduced heart rate variability and vagal tone in anxiety: Trait versus state, and the effects of autogenic training. Autonomic Neuroscience. 2009; 145:99-103. [PubMed: 19059813]

Morgan CN, Roy M, Chance P. Psychiatric comorbidity and medication use in autism: A community survey. Psychiatric Bulletin. 2003; 27(10):378-381.10.1192/pb.02-031

O'Brien P, Oyebode F. Psychotropic medication and the heart. Advances in Psychiatric Treatment. 2003; 9(6):414-423.10.1192/apt.9.6.414

Patriquin MA, Scarpa A, Friedman BH, Porges SW. Respiratory sinus arrhythmia: A marker for positive social functioning and receptive language skills in children with autism spectrum disorders. Developmental Psychobiology, E-pub ahead of print. 201110.1002/dev.21002

Paul R, Dykens E, Leckman JF, Watson M, Breg WR, Cohen DJ. A comparison of language characteristics of mentally retarded adults with fragile $\mathrm{X}$ syndrome and those with nonspecific mental retardation and autism. Journal of Autism and Developmental Disorders. 1987; 17(4):457468. [PubMed: 3479423]

Pieretti M, Zhang FP, Fu YH, Warren ST, Oostra BA, Caskey CT. Absence of expression of the FMR-1gene in fragile X syndrome. Cell. 1991; 66:817-822. [PubMed: 1878973]

Porges SW. The polyvagal perspective. Biological Psychology. 2007; 74(2):116-143. [PubMed: 17049418]

Porges, SW.; Bohrer, RE. Analyses of periodic processes in psychophysiological research. In: Cacioppo, JT.; Tassinary, LG., editors. Principles of psychophysiology: Physical, social, and inferential elements. New York: Cambridge University Press; 1990. p. 708-753.

Porges SW, Furman SA. The early development of the autonomic nervous system provides a neural platform for social behavior: A polyvagal perspective. Infant and Child Development. 2011; 20(1): 106-118. [PubMed: 21516219]

Porges, SW.; Macellaio, M.; Stanfill, SD.; McCue, K.; Lewis, GF.; Harden, ER.; Heilman, KJ. Respiratory sinus arrhythmia and auditory processing in autism: Modifiable deficits of an integrated social engagement system?. International Journal of Psychophysiology. 2013. E-pub ahead of print(0)http://dx.doi.org/10.1016/j.ijpsycho.2012.11.009

Prutting CA. Pragmatics as social competence. Journal of Speech Language and Hearing Disorders. 1982; 47(2):123-134.

Rechlin T. Effects of psychopharmacologic therapy on heart rate variation. Nervenarzt. 1995; 66:678685. [PubMed: 7477605]

Reiss AL, Dant CC. The behavioral neurogenetics of fragile X syndrome: Analyzing gene-brainbehavior relationships in child developmental psychopathologies. Development and Psychopathology. 2003; 15:927-968. [PubMed: 14984133]

Roberts J, Miranda M, Boccia M, Janes H, Tonnsen B, Hatton D. Treatment effects of stimulant medication in young boys with fragile $\mathrm{X}$ syndrome. Journal of Neurodevelopmental Disorders. 2011; 3(3):175-184.10.1007/s11689-011-9085-4 [PubMed: 21671049] 
Roberts JE, Boccia ML, Bailey DB, Hatton DD, Skinner M. Cardiovascular indices of physiological arousal in boys with fragile X syndrome. Developmental Psychobiology. 2001; 39(2):107-123. [PubMed: 11568881]

Roberts JE, Boccia ML, Hatton DD, Skinner ML, Sideris J. Temperament and vagal tone in boys with fragile X syndrome. Developmental and Behavioral Pediatrics. 2006; 27(3):193-201.

Roberts JE, Martin GE, Moskowitz L, Harris AA, Foreman J, Nelson L. Discourse skills of boys with fragile X syndrome in comparison to boys with Down syndrome. Journal of Speech, Language, and Hearing Research. 2007; 50:475-492.

Roberts JE, Mazzocco MM, Murphy MM, Hoehn-Saric R. Arousal modulation in females with fragile X or Turner syndrome. Journal of Autism and Developmental Disorders. 2008; 38:20-27. [PubMed: 17340202]

Roberts JE, Tonnsen B, Robinson A, Shinkareva SV. Heart activity and autistic behavior in infants and toddlers with fragile X syndrome. American Journal on Intellectual and Developmental Disabilities. 2012; 117(2):90-102. [PubMed: 22515825]

Rogers SJ, Wehner DE, Hagerman R. The behavioral phenotype in fragile X: Symptoms of autism in very young children with fragile $\mathrm{X}$ syndrome, idiopathic autism, and other developmental disorders. Journal of Developmental Behavioral Pediatrics. 2001; 22(6):409-417. [PubMed: 11773805]

Roid, GH.; Miller, LJ. Leiter International Performance Scale-Revised. Wood Dale, IL: Stoelting; 1997.

Ross DE. Replacing faulty conversational exhanges for children with autism by establishing a functionally equivalent alternative response. Eduation and Training in Mental Retardation and Developmental Disabilities. 2002; 37(4):343-362.

Rubin, KH.; Burgess, KB., editors. Social withdrawal and anxiety. New York: Oxford University Press; 1991.

Schuler, A.; Prizant, B. Echolalia. In: Schopler, E.; Mesibov, G., editors. Communication problems in autism. New York: Plenum Press; 1985. p. 163-184.

Sigman M, Dissanayake C, Corona R, Espinosa M. Social and cardiac responses in young children with autism. Autism. 2003; 7(2):205-216. [PubMed: 12846388]

Silke B, Campbell C, King D. The potential cardiotoxicity of antipsychotic drugs as assessed by heart rate variability. Journal of Psychopharmacology. 2002; 16(4):355-360. [PubMed: 12503835]

Sudhalter V, Belser RC. Conversational characteristics of children with fragile X syndrome: Tangential language. American Journal on Mental Retardation. 2001; 106(5):389-400. [PubMed: 11531459]

Sudhalter V, Cohen IL, Silverman W, Wolf-Schein EG. Conversational analyses of males with fragile $\mathrm{X}$, Down syndrome, and autism: Comparison of the emergence of deviant language. American Journal on Mental Retardation. 1990; 94(4):431-441. [PubMed: 2137003]

Suess PE, Bornstein MH. Task-to-task vagal regulation: Relations with language and play in 20month-old children. Infancy. 2000; 1(3):303-322.

Tager-Flusberg H. Once upon a ribbit: Stories narrated by autistic children. British Journal of Developmental Psychology. 1995; 13:45-59.

Tager-Flusberg H, Anderson M. The development of contingent discourse ability in autistic children. Journal of Child Psychology and Psychiatry. 1991; 32:1123-1134. [PubMed: 1838537]

Tager-Flusberg, H.; Paul, R.; Lord, C. Language and communication in autism. In: Volkmar, F.; Paul, R.; Klin, A., editors. Handbook on autism and pervasive developmental disorders. 3. New York: Wiley; 2005. p. 335-364.

Toichi M, Kamio Y. Paradoxical autonomic response to mental tasks in autism. Journal of Autism and Developmental Disorders. 2003; 33(4):417-426. [PubMed: 12959420]

Tyrer PL, Alexander J. Awareness of cardiac function in ancious, phobic, and hypochandriacal patients. Psychological Medicine. 1980; 10:171-174. [PubMed: 7384320]

Valdovinos M, Parsa R, Alexander M. Results of a nation-wide survey evaluating psychotropic medication use in fragile X syndrome. Journal of Developmental and Physical Disabilities. 2009; 21(1):23-37. 
Van Hecke AV, Lebow J, Elgiz B, Damon L, Harden E, Kramer A, Porges SW. Electroencephalogram and heart rate regulation to familiar and unfamiliar people in children with autism spectrum disorders. Child Development. 2009; 80(4):1118-1133. [PubMed: 19630897]

van Steensel F, Bögels S, Perrin S. Anxiety disorders in children and adolescents with autistic spectrum disorders: A meta-analysis. Clinical Child and Family Psychology Review. 2011; 14(3):302-317. [PubMed: 21735077]

Volden J. Conversational repair in speakers with autism spectrum disorder. International Journal of Language \& Communication Disorders. 2004; 39(2):171-189. [PubMed: 15204450]

Watson L, Roberts J, Baranek G, Mandulak K, Dalton J. Behavioral and physiological responses to child-directed speech of children with autism spectrum disorders or typical development. Journal of Autism and Developmental Disorders. 2012; 42(8):1616-1629. [PubMed: 22071788]

Watson LR, Baranek GT, Roberts JE, David FJ, Perryman TY. Behavioral and physiological responses to child-directed speech as predictors of communication outcomes in children with autism spectrum disorders. Journal of Speech, Language, and Hearing Research. 2010; 53(4):10521064.

Wechsler, D. Wechsler Abbreviated Scale of Intelligence (WASI). UK: Pearson Assessment; 1999.

White SW, Oswald D, Ollendick T, Scahill L. Anxiety in children and adolescents with autism spectrum disorders. Clinical Psychology Review. 2009; 29(3):216-229.10.1016/j.cpr. 2009.01.003 [PubMed: 19223098]

Williams, KT. Expressive Vocabulary Test. Circle Pines, MN: American Guidance Service; 1997.

Wolf-Schein EG, Sudhalter V, Cohen IL, Fisch GS, Hanson D, Pfadt AG, Brown WT. Speechlanguage and the fragile X syndrome: Initial findings. ASHA. 1987; 29(7):35-38. [PubMed: 2956959]

Woodard CR, Goodwin MS, Zelazo PR, Aube D, Scrimgeour M, Ostholthoff T, Brickley M. A comparison of autonomic, behavioral, and parent-report measures of sensory sensitivity in young children with autism. Research in Autism Spectrum Disorders. 2012; 6(3):1234-1246.

Zajac DJ, Harris AA, Roberts JE, Martin GE. Direct magnitude estimation of articulation rate in boys with fragile X syndrome. Journal of Speech, Language, and Hearing Research. 2009; 52:13701379 . 


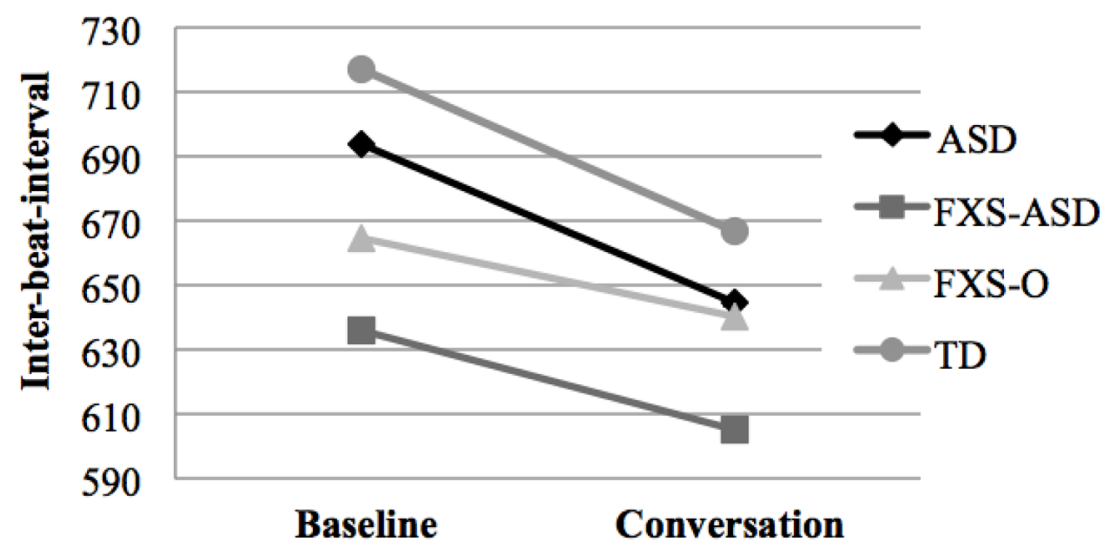

Figure 1.

Mean Inter-beat-interval Estimates across Groups

Note. Means adjusted for chronological age. ASD = autism spectrum disorder; FXS-ASD = fragile $\mathrm{X}$ syndrome with autism spectrum disorder; FXS-0 = fragile $\mathrm{X}$ syndrome without autism spectrum disorder; TD = typical development. 


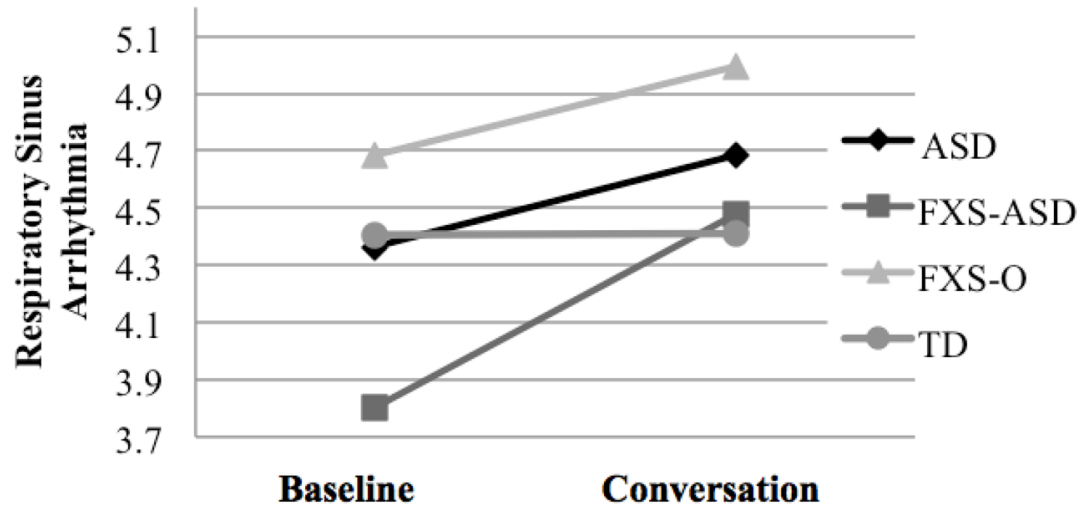

Figure 2.

Mean Respiratory Sinus Arrhythmia Estimates across Groups

Note. Means adjusted for chronological age. ASD = autism spectrum disorder; FXS-ASD = fragile $\mathrm{X}$ syndrome with autism spectrum disorder; $\mathrm{FXS}-\mathrm{O}=$ fragile $\mathrm{X}$ syndrome without autism spectrum disorder; TD = typical development. 
Table 1

Group Characteristics

\begin{tabular}{|c|c|c|c|}
\hline & & Group & \\
\hline & $\begin{array}{c}\text { ASD } \\
n=40\end{array}$ & $\begin{array}{c}\text { FXS } \\
n=39\end{array}$ & $\underset{n=28}{\text { TD }}$ \\
\hline Chronological age in years & $10.11(2.96)^{\mathrm{a}}$ & $11.90(2.46)^{\mathrm{b}}$ & $8.84(2.41)^{\mathrm{a}}$ \\
\hline$M(S D)$, range & $4.08-14.56$ & $6.47-15.89$ & $4.02-13.68$ \\
\hline Nonverbal mental age ${ }^{l}$ & $8.67(3.96)^{\mathrm{a}}$ & $5.14(0.60)^{\mathrm{b}}$ & $10.17(3.91)^{\mathrm{a}}$ \\
\hline$M(S D)$, range & $4.67-19.67$ & $3.50-6.67$ & $5.17-18.83$ \\
\hline Receptive vocabulary age ${ }^{2}$ & $8.58(4.50)^{\mathrm{a}}$ & $6.29(1.45)^{b}$ & $12.63(5.21)^{\mathrm{c}}$ \\
\hline$M(S D)$, range & $2.58-22.00$ & $3.92-9.33$ & $5.67-22.00$ \\
\hline Expressive vocabulary age $^{3}$ & $7.79(3.73)^{\mathrm{a}}$ & $5.43(1.22)^{\mathrm{b}}$ & $10.57(4.16)^{\mathrm{c}}$ \\
\hline$M(S D)$, range & $3.17-19.75$ & $3.58-8.25$ & $5.42-22.00$ \\
\hline \multicolumn{4}{|l|}{ Medication $\%$} \\
\hline Antidepressant & 2.5 & 7.7 & 0 \\
\hline Stimulant & 7.5 & 10.3 & 0 \\
\hline Antipsychotic & 0 & 5.1 & 0 \\
\hline Antianxiety & 0 & 2.6 & 0 \\
\hline Alpha adrenergic agonist & 2.5 & 0 & 0 \\
\hline More than one & 17.5 & 15.4 & 0 \\
\hline \multicolumn{4}{|l|}{ Race $\%$} \\
\hline Caucasian & 87.2 & 88.9 & 78.6 \\
\hline African American & 7.7 & 0 & 7.1 \\
\hline Asian & 0 & 8.3 & 0 \\
\hline Multiracial & 2.6 & 2.8 & 10.7 \\
\hline Other & 2.6 & 0 & 3.6 \\
\hline \multicolumn{4}{|l|}{ Income $\%$} \\
\hline$<20 \mathrm{k}$ & 6.9 & 0 & 5.6 \\
\hline $20 \mathrm{k}-39 \mathrm{k}$ & 20.7 & 4.2 & 5.6 \\
\hline $40 \mathrm{k}-59 \mathrm{k}$ & 6.9 & 12.5 & 22.2 \\
\hline $60 \mathrm{k}-79 \mathrm{k}$ & 24.1 & 16.7 & 16.7 \\
\hline$>80 \mathrm{k}$ & 41.4 & 66.7 & 50 \\
\hline \multicolumn{4}{|l|}{ Maternal education level \% } \\
\hline High school & 25.7 & 16.7 & 13.6 \\
\hline Associate & 17.1 & 11.1 & 9.1 \\
\hline Bachelor & 37.1 & 44.4 & 31.8 \\
\hline Master & 17.1 & 19.4 & 36.4 \\
\hline Doctorate & 2.9 & 8.3 & 9.1 \\
\hline
\end{tabular}

Am J Intellect Dev Disabil. Author manuscript; available in PMC 2014 November 01. 
Note.

${ }^{l}$ Leiter International Performance Scale-Revised,

2 Peabody Picture Vocabulary Test,

3 Expressive Vocabulary Test. ASD = autism spectrum disorder; FXS = fragile $\mathrm{X}$ syndrome; TD = typical development. Means in the same row with different superscripts differ significantly at $p<.05$. 


\section{Table 2}

Descriptive Statistics of Cardiac Indices Across Conditions and Groups

\begin{tabular}{|c|c|c|c|}
\hline \multirow[t]{2}{*}{ Cardiac index } & \multirow[t]{2}{*}{ Group } & \multicolumn{2}{|c|}{ Estimate } \\
\hline & & Observed $M(S E)$ & Adjusted $M(S E)$ \\
\hline \multirow[t]{3}{*}{ Baseline IBI } & ASD & $690.373(128.06)$ & $693.32(17.95)$ \\
\hline & FXS & $654.18(100.77)$ & $642.29(19.15)$ \\
\hline & $\mathrm{TD}$ & $702.00(122.42)$ & $715.84(22.41)$ \\
\hline \multirow[t]{3}{*}{ Conversation IBI } & ASD & $641.29(78.74)$ & $644.45(12.82)$ \\
\hline & FXS & $627.21(84.12)$ & $612.75(13.68)$ \\
\hline & TD & $649.34(90.40)$ & $665.27(16.01)$ \\
\hline \multirow[t]{3}{*}{ Change IBI (baseline - conversation) } & ASD & $49.43(76.34)$ & $49.11(10.56)$ \\
\hline & FXS & $33.13(44.20)$ & $34.60(11.27)$ \\
\hline & $\mathrm{TD}$ & $53.37(75.97)$ & $51.79(13.18)$ \\
\hline \multirow[t]{3}{*}{ Baseline RSA } & ASD & $4.35(1.38)$ & $4.36(0.22)$ \\
\hline & FXS & $4.01(1.34)$ & $3.99(0.23)$ \\
\hline & $\mathrm{TD}$ & $4.35(1.42)$ & $4.37(0.27)$ \\
\hline \multirow[t]{3}{*}{ Conversation RSA } & ASD & $4.69(1.18)$ & $4.68(0.18)$ \\
\hline & FXS & $4.55(1.10)$ & $4.59(0.19)$ \\
\hline & $\mathrm{TD}$ & $4.43(1.05)$ & $4.39(0.22)$ \\
\hline \multirow[t]{3}{*}{ Change RSA (baseline - conversation) } & ASD & $-0.40(1.12)$ & $-0.39(0.17)$ \\
\hline & FXS & $-0.50(1.01)$ & $-0.56(0.18)$ \\
\hline & TD & $-0.08(0.94)$ & $-0.02(0.21)$ \\
\hline
\end{tabular}

Note. Adjusted means depict estimates controlling for chronological age. ASD = autism spectrum disorder; FXS = fragile X syndrome; TD = typical development. 


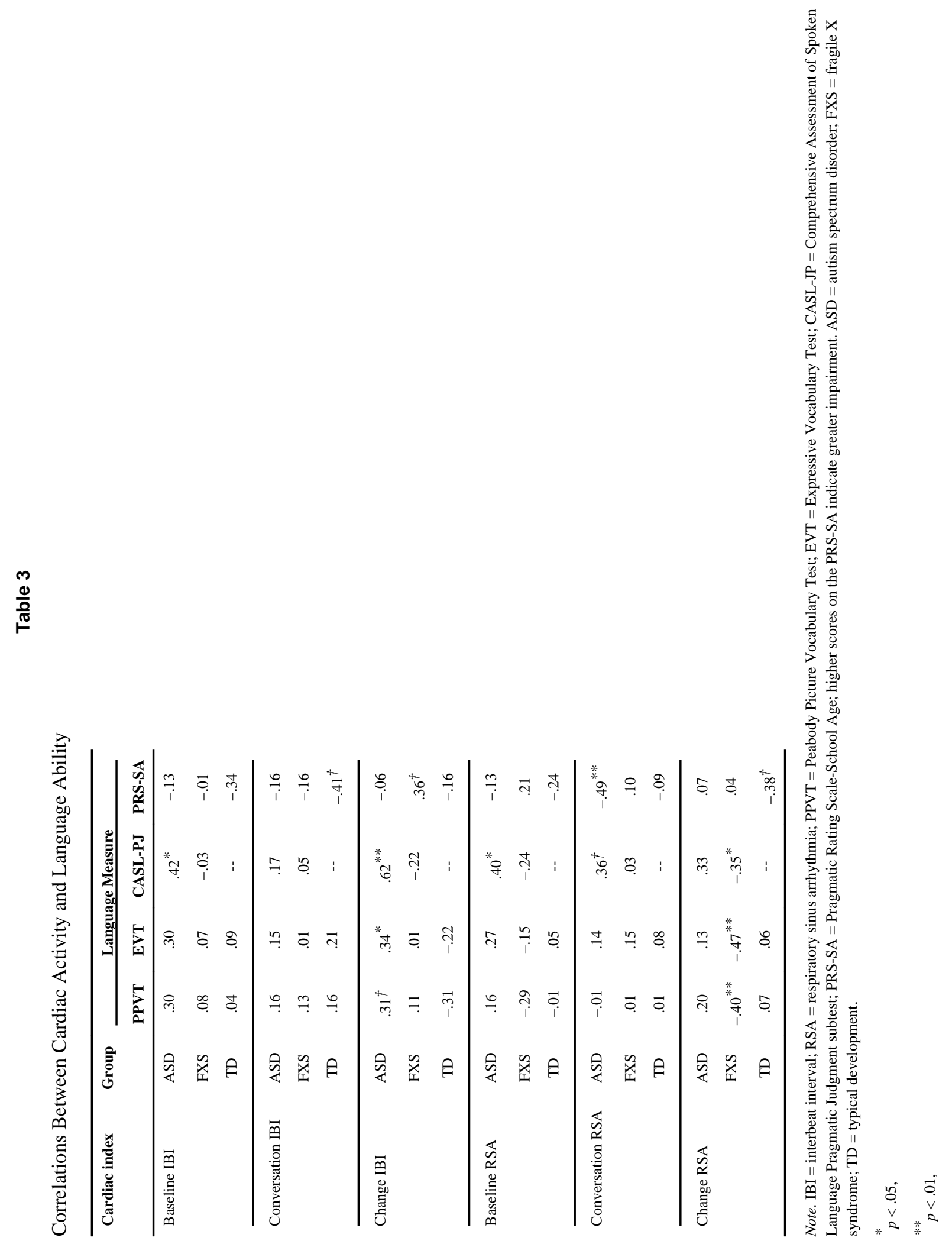


